\title{
Chemical Control of the Lesser Date Moth, Batrachedra amydraula (Lepidoptera: Batrachedridae)
}

\author{
M. JAVADZADEH and A. HOSSEINI-GHARALARI* \\ Agricultural Entomology Research Department, Iranian Research Institute of Plant Protection, \\ Agricultural Research, Education and Extension Organization (AREEO), \\ Yaman St., Chamran Hwy., Tehran, Iran
}

(Received: 27 December 2016; accepted: 17 January 2017)

\begin{abstract}
The Lesser Date Moth, Batrachedra amydraula (Lepidoptera: Batrachedridae), is a key pest of date palms in silos and storages. The efficacy of aluminium phosphide (Phostoxin ${ }^{\circledR}$ tablet $55 \%$ ) @ $5 \mathrm{t} / \mathrm{m}^{3}$ and magnesium phosphide (Degesch® plates 56\%) @ $2 \mathrm{p} / 30 \mathrm{~m}^{3}$ were assessed against this pest in Iran date silos based on a completely randomized block design. Based on Henderson-Tilton formula, on the third day after treatment, both treatments resulted in $100 \%$ mortality. Application of magnesium phosphide and aluminium phosphide can be a suitable substitution for methyl bromide, which has just been banned in many countries.
\end{abstract}

Keywords: Lesser Date Moth, Batrachedra amydraula, phostoxin, magnesium phosphide.

Key message:

Application of magnesium phosphide and aluminium phosphide can be a suitable substitution for methyl bromide, which has just been banned in many countries.

Stored-product pests can cause serious damage in silos and storages, if here are not controlled properly. The Lesser Date Moth, Batrachedra amydraula (Lepidoptera: Batrachedridae), is a key pest of date palm (Phoenix dactylifera L.) in date palm orchards and silos in the Middle East and North Africa including Iraq, Saudi Arabia, United Arab Emirates, Qatar, Bahrain, Oman, Jordan, Egypt, Libya, Tunisia, Iran and India (Michael, 1970; Blumberg, 1975; Dowson, 1982; Elwan, 2000; Al-Zadjali et al., 2006; Blumberg, 2008; Latifian and Nejadian, 2009). The adult moths have a wing span of 10-14 mm. The front wings are lanceolate with brownish scales. The hind wings are narrow, light grey and longfringed. The eggs are small, light yellow and are laid singly on the flowers and immature fruits. The larvae, when full grown, are about 10-12 mm long. The head and the prothorax are light brown while the rest of the body is translucent white. The prolegs are on the abdominal segments 3-4 and on the last one. Pupae are slender, long and light-brown in color (Harhash et al., 2003). Its biology has been studied by several researchers (Shayesteh et al. 2010). Population density and fluctuation of this pest is determined by pheromone

* Corresponding author; e-mail: ahosseinig@gmail.com 
traps (Levi-Zada et al., 2011, 2012; Al-Jorany et al., 2015). The Lesser Date Moth larvae attack inflorescences and newly set green fruits. The larvae make a hole near fruit calyx and feed on soft pulp and immature seeds (Levi-Zada et al., 2011). Infested fruit becomes darken, and fall to the ground within four weeks after attack; the branches stop growing and eventually turned into dry. Lesser Date Moth early season infestation causes significant fruit drops and losses of up to $75 \%$ of the yield (Michael, 1970; Blumberg, 1975). It can also cause serious damage in the silos, where chemical application becomes necessary.

Application of methyl bromide against stored-product pest has been banned since 2015 in many countries. Therefore, it is necessary to find suitable substitutions for this pesticide. One of the candidates is phosphine or hydrogen phosphide $\left(\mathrm{PH}_{3}\right)$. It is a low molecular weight, low boiling point compound that diffuses rapidly and penetrates deeply into materials, such as large bulks of grain or tightly packed materials. The gas is produced from formulations of metallic phosphides (usually aluminium phosphide $\left(\mathrm{AIP}+3 \mathrm{H}_{2} \mathrm{O}=\mathrm{PH}_{3}^{\wedge}+\mathrm{Al}(\mathrm{OH})_{3}\right)$ or magnesium phosphide $\left(\mathrm{Mg}_{3} \mathrm{P}_{2}\right.$ $\left.+6 \mathrm{H}_{2} \mathrm{O}=2 \mathrm{PH}_{3} \wedge+3 \mathrm{Mg}(\mathrm{OH})_{2}\right)$ that contain additional materials for regulating release of the gas. Aluminium phosphide is formulated as tablets, pellets or small sachets of powder with additional materials such as ammonium carbamate, ammonium bicarbonate, urea and paraffin to regulate release of fumigant and suppress flammability. The magnesium phosphide is similarly manufactured in tablets or pellets. It is also prepared in flat plates; here the formulation is embedded in a plastic matrix that regulates access of moisture and hence controls release of the gas. After the phosphine has evolved from a formulation, the residue that remains consists mainly of aluminium or magnesium hydroxide. Small amounts of undecomposed aluminium phosphide may also remain in the grey white dust from tablets, pellets or sachets. Application of aluminium phosphide and magnesium phosphide shall be done carefully due to their high acute inhalation toxicity to human. In addition to their toxic properties, the gas will corrode certain metals and may ignite spontaneously in air at concentrations above its lower flammable limit. The goal of this research was to study the efficacy of aluminium phosphide and magnesium phosphide against B. amydraula in palm date silos.

\section{Materials and Methods}

The research was conducted based on a completely randomized design with 3 treatments and 7 replications during 2008 in Shahdah (Kermanshah, Iran). Treatments were 1.) aluminium phosphide (Phostoxin $®$ tablet $55 \%) @ 5 \mathrm{t} / \mathrm{m}^{3}, 2$.) magnesium phosphide (Degesch ${ }^{\circledR}$ plates 56\%) @ 2 p/30 $\mathrm{m}^{3}$ and 3) control (no-spray treatment). The research was conducted in a highly-infested date silo. For each replication of aluminium phosphide treatment, a $1-\mathrm{m}^{3}$ plastic container was used, in which 200 dates were put. The dates were chosen from the infested silo. For each replication of magnesium phosphide treatment, a $30-\mathrm{m}^{3}$ room was prepared and 200 dates were put in the center of the room in a plastic box. The number of insects was counted one day before treatment and also $72 \mathrm{~h}$ after application. The efficacy of treatments was estimated based on the Henderson-Tilton formula (Henderson and Tilton, 1955): 


$$
\text { Efficacy } \%=100 \times[1-(T a \times C b) /(T b \times C a)]
$$

where, $T a$ is the number of insects in treated plot after treatment, $C b$ is the number of insects in control plot before treatment, $T b$ is the number of insects in treated plot before treatment, and $\mathrm{Ca}$ is the number of insects in control plot after treatment.

Data were analyzed using procedures of SAS (SAS Institute Inc., 2002). The normality of the untransformed and transformed data and also normality of residuals after analysis of variance were checked using stem-leaf and normal probability plots. Homoscedasticity was checked by observing graphical distribution plots of variance by mean (PROC PLOT). A General Linear Model (PROC GLM) was used to compare the efficacy of the treatments $(\alpha=0.05)$.

\section{Results and Discussion}

The analysis of variance showed that there was not a significant difference among treatments on the third day after the application $\left(\mathrm{F}_{1,12}=0.0, \mathrm{P}=1\right)$. Both treatments caused $100 \%$ mortality. Lysandrou et al. (2010) studied the efficacy of spinosyns, spinosad (Tracer ${ }^{\circledR}$ 240SC) and spinetoram (Radiant ${ }^{\circledR} 120 \mathrm{SC}$ ), and the insect growth regulator methoxyfenozide (Runner ${ }^{\circledR}$ 240SC) against Lesser Date Moth. Fruit infestation ranged from 17.2 to $24.2 \%$ after six weeks and the spray regime of two applications at a 14 day interval per season showed that spinosad at $4.8 \mathrm{~g}$ ai/100 $\mathrm{L}$ was equivalent to spinetoram at $1.8 \mathrm{~g}$ ai/ $100 \mathrm{~L}$. Spinosyns were very effective applied alone, and spinetoram was 2.7- to 4-fold more active than spinosad. All products performed well under dry conditions with high temperatures reaching $51{ }^{\circ} \mathrm{C}$ without any phytotoxicity symptoms either on the fruit or the tree foliage.

Insects can develop resistance to gas insecticides which are applied in pest management programs. For example, Winks (1974) showed that Tribolium castaneum (Coleoptera: Tenebrionidae) could develop 10-fold resistance to phosphine in six generations. Resistance may occur in immature stages as well as in adult insects. Bell et al. (1977) found a good correlation between resistance in the adult stage of Rhyzopertha dominica (Coleoptera: Bostrichidae) and resistance in the egg stage. Champ and Dyte (1976) found evidence of resistance to phosphine in insects from several parts of the world, particularly where inadequate techniques of fumigation were employed, and they indicated that emergence of resistance to fumigants under practical conditions was a matter of great concern. There is evidence (Borah and Chalal, 1979; Tyler et al., 1983) of the development of resistance to phosphine in field populations of Khapra beetle and other insects infesting stored grain. Based on our study, for the Lesser Date Moth, aluminium phosphide and magnesium phosphide can be used in rotation to reach an acceptable control level.

\section{Compliance with Ethical Standards:}

Funding: This study was not funded by any organization.

Conflict of Interest: All authors declares that they no conflict of interest.

Ethical approval: This article does not contain any studies with human participants or animals performed by any of the authors. 


\section{Literature}

Al-Jorany, R. S., Al-Jboory, I. J. and Hassan, N. (2015): Evaluation of the sex pheromone efficiency of the Lesser Date Moth, Batrachedra amydraula Meyrick (Lepidoptera: Batrachedridae), in Baghdad, Iraq. J. Life Sciences 9, 242-247.

Al-Zadjali, T. S., Abdallah, F. F. and El-Haidari, H. (2006): Insect pests attacking date palms and dates in Sultanate of Oman. Egyp. J. Agric. Res. 84, 51-59.

Bell, C. H., Hole, B. D. and Evans, P. H. (1977): The occurrence of resistance to phosphine in adult and egg stages of strains of Rhyzopertha dominica (F.) (Coleoptera: Bostrichidae). J. Stored Prod. Res. 13, 91-94.

Blumberg, D. S. (1975): Preliminary notes on the phenology and biology of Batrachedra amydraula Mery. (Lepidoptera: Cosmopterygidae), a new pest of date palms in Israel. Phytoparastica 3, 55-57.

Blumberg, D. (2008): Review: Date palm arthropod pests and their management in Israel. Phytoparasitica 36, 411-448.

Borah, B. and Chalal, B. S. (1979): Development of resistance in Trogoderma granarium Everts to phosphine in the Punjab. FAO Plant Prot. Bull., 27, 77-80.

Champ, B. R. and Dyte, C. E. (1976): Report of the FAO global survey of pesticide susceptibility of stored grain pests. FAO Plant Production and Protection Series No. 5, FAO, Rome. 297 p.

Dowson, V. H. W. (1982): Date production and protection: with special reference to North Africa and the Near East. Food and Agriculture Organization of the United Nations, Rome, FAO. Plant production and protection paper, 35, 1-294.

Elwan, A. A. (2000): Survey of the insect and mites pests associated with date palm trees in AL-Dakhliya Region, Sultanate of Oman. Egypt J. Agric. Res. 78, 653-664.

Harhash, M., Mourad, A. K. and Hammad, S. M. (2003): Integrated crop management of the lesser date moth Batrachedra amydraula Meyr. (Lepidoptera: Cosmopteridae) infesting some date-palm varieties in Egypt. Commun. Agric. Appl. Biol. Sci. 68, 209-221.

Henderson, C. F. and Tilton, E. W. (1955): Tests with acaricides against the brown wheat mite. J. Econ. Entomol. 48, 157-161.

Latifian, M. and Nejadian, E. S. (2009): Study of the lesser moth Batrachedra amydraula (Lepidoptera: Batrachedridae) distribution based on geostatistical models in Khuzestan Province. J. Entomological Res. $1,43-55$.

Levi-Zada, A., Fefer, D., Anshelevitch, L., Litovsky, A., Bengtsson, M., Gindin, G. and Soroker, V. (2011): Identification of the sex pheromone of the lesser date moth, Batrachedra amydraula, using sequential SPME auto-sampling. Tetrahedron Lett. 52, 4550-4553.

Levi-Zada, A., Sadowsky, A., Dobrinin, S., David, M., Ticuchinski, T., Fefer, D., Greenberg, A. and Blumberg, D. (2012): Reevaluation of the sex pheromone of the lesser date moth, Batrachedra amydraula, using autosampling SPME-GC/MS and field bioassays. Chemoecology 23, 13-20.

Lysandrou, M., Temerak, S. A. and Sayed, A. A. (2010): The use of different insect control regimes using three green chemicals to combat Batrachedra amydraula and Cadra on date palm fruit in Egypt. Acta Hortic. $882,481-489$.

Michael, I. F. (1970): Economic importance and control of Batracherda amydraula Mery. (The Lesser Date Moth) in the U.A.R. Date Growers Inst. Rep. 47, 9-10.

SAS Institute Inc. (2002): SAS/STAT user's guide. Version 9.1. SAS Institute Inc., Cary, North Carolina.

Shayesteh, N., Marouf, A. and Amir-Maafi, M. (2010): Some biological characteristics of the Batrachedra amydraula Meyrick (Lepidoptera: Batrachedridae) on main varieties of dry and semi-dry date palm of Iran. Proc. of the 10th International Working Conference on Stored Product Protection, Lisbon, Portugal. pp. 151-155.

Tyler, P. S., Taylor, R. W. and Rees, D. P. (1983): Insect resistance to phosphine fumigation in food warehouses in Bangladesh. Int. Pest Control, 25, 10-21.

Winks, R. G. (1974): Characteristics of response of grain pests to phosphine. Annual Report 1973-1974. Canberra, Commonwealth Scientific and Industrial Research Organization, Division of Entomology. 